\title{
A ABORDAGEM DE DUAS DOENÇAS NEGLIGENCIADAS: HANSENÍASE E TUBERCULOSE NOS LIVROS DIDÁTICOS DE ENSINO MÉDIO APROVADOS PELO PROGRAMA NACIONAL DO LIVRO DIDÁTICO PARA O ENSINO MÉDIO (PNLDEM)
}

\author{
THE APPROACH OF TWO NEGLECTED DISEASES: TUBERCULOSIS AND \\ LEPROSY IN HIGH SCHOOL TEXTBOOKS APPROVED BY THE \\ NATIONAL TEXTBOOK PROGRAM FOR HIGH SCHOOL (PNLDEM) \\ Pedro Henrique Lopes da Silva ${ }^{1}$, Cristina dos Santos Bianchi ${ }^{2}$ \\ ${ }^{1}$ SEEDUC/RJ/FIOCRUZ/RJ/peddro.henrique10@ gmail.com \\ ${ }^{2}$ SEEDUC/RJ/ UERJ, crisbianchibr@yahoo.com.br
}

\begin{abstract}
RESUMO
Doenças negligenciadas são doenças transmitidas por agentes infecciosos e parasitários que prevalecem na pobreza, e contribuem para a manutenção das desigualdades atuais, em alusão essencialmente ao acesso à saúde. A tuberculose e a hanseníase são exemplos destas doenças e são alvos deste estudo, que tem como objetivo a análise da abordagem destas duas doenças negligenciadas, bem como a problemática da tuberculose multirresistente, nos livros didáticos de Ensino Médio aprovados pelo Programa Nacional do Livro Didático - PNLDEM. Os oito livros didáticos aprovados, pelo PNLD 2012, foram analisados. Após a investigação, foi verificado que $62,5 \%$ dos livros trataram de alguma forma a tuberculose e $50 \%$ a hanseníase, um índice insatisfatório. Além disso, a abordagem dos conteúdos analisados foi considerada incompleta, pois em tese não contribui para uma aprendizagem significativa, já que não traz uma abordagem histórico-filosófica e social do tema.
\end{abstract}

Palavras-chave: doenças negligenciadas; tuberculose; hanseníase; livros didáticos.

\begin{abstract}
Neglected diseases are transmitted by infectious and parasites agents that prevail in poverty, and contribute to the maintenance of current inequalities, mainly with regard to access to quality healthcare. Tuberculosis and leprosy are examples of these diseases and are targets of this study, which aims to approach the analysis of these two neglected diseases, as well as the problem of multidrug-resistant tuberculosis in high school textbooks approved by the National Textbook Program - PNLDEM. Eight textbooks, selected according to the PNLDEM 2012 were analyzed. After investigation, it was found that $62,5 \%$ of the books treated somehow Tuberculosis and leprosy 50\%, a unsatisfactory rate. Moreover, the approach of content analysis was considered incomplete because in theory the textbooks don't contribute for meaningful learning, since it doesn't brings a historical-philosophical and social approach to the subject.
\end{abstract}

Key words: neglected diseases; tuberculosis; leprosy; textbooks.

\section{INTRODUÇÃO}

Segundo os Parâmetros Curriculares Nacionais, em Ciências Naturais: o desenvolvimento de posturas e valores envolvem muitos aspectos da vida social, 
cultural, do sistema produtivo e das relações entre os seres humanos e a natureza. (BRASIL, 1998). A valorização da vida em sua diversidade, a responsabilidade em relação à saúde e ao ambiente, a consideração de variáveis que envolvem um fato, o respeito às provas obtidas por investigação e à diversidade de opiniões são elementos que contribuem para aprendizagem de atitudes, bem como para saber se posicionar crítica e construtivamente diante de diferentes questões. E uma das questões brasileiras que merecem o foco de atenções, sobretudo no ensino de ciências e biologia, são as doenças negligenciadas.

O conceito de doenças negligenciadas é novo e polêmico. Ele foi proposto inicialmente na década de 1970, por um programa da Fundação Rockefeller como "The Great Neglected Diseases". A definição básica é que estas são doenças que prevalecem na pobreza, e contribuem para a manutenção das desigualdades atuais, no que diz respeito essencialmente ao acesso à saúde.

Trata-se então de doenças negligenciadas, sobretudo, pelo poder público, transmitidas por agentes parasitários e infecciosos como vírus, bactérias, protozoários e helmintos que atingem principalmente a população de baixa renda, o que acaba aumentando os riscos de marginalização da mesma. No Brasil, o Programa de Pesquisa e Desenvolvimento em Doenças Negligenciadas no Brasil, definiu em 2006 a lista com as sete doenças que compõem o quadro de prioridades no programa de doenças negligenciadas, elas são: dengue, doença de Chagas, leishmaniose, malária, esquistossomose, hanseníase e tuberculose (MINISTÉRIO DA SAÚDE, 2010).

As pessoas que vivem em comunidades às margens da pobreza também são mais atingidas pela precariedade do sistema público de saúde, no que diz respeito ao diagnóstico e tratamento da doença e, em consequência, têm menos possibilidades de acesso ao tratamento adequado, e assim à cura. No Brasil, a prevalência da tuberculose e suas taxas de mortalidade refletem padrões socioeconômicos mais amplos, com os pobres e as comunidades desfavorecidas sofrendo o maior impacto (SANTOS e GOMES, 2007), e atualmente possui o agravante da tuberculose multirresistente. Esta tem sido uma preocupação crescente entre as autoridades de saúde por todo o mundo, o tratamento é caro, longo e complexo, o que agrava o quadro (COELHO et al., 2012).

As multiplicações contínuas do M. tuberculosis geram alterações espontâneas no seu material genético, levando em alguns casos, a modificações no local de atuação de determinado medicamento, caracterizando deste modo, a resistência natural. Um a cada $10^{5}-10^{7}$ bacilos é naturalmente resistente à isoniazida, e um a cada $10^{7}-10^{9}$ é 
resistente à rifampicina - rifampicina e isoniazida são os dois principais medicamentos utilizados, universalmente, para o tratamento da doença.

Por meio desta análise, é possível concluir que a multirresistência não é um fenômeno natural, pois seria necessária uma população bacilar de $10^{14}$ para um bacilo se tornar naturalmente resistente à rifampicina e isoniazida, e $10^{19}$ para rifampicina, isoniazida e etambutol - substância bacterioestática - números impossíveis de se alojarem no corpo humano. Quando tal fenômeno ocorre, consequentemente ao uso inadequado dos esquemas terapêuticos, quer por irregularidade quer por baixa potência, dá-se o nome de resistência pós-primária ou secundária, que sempre decorre de falha humana: por parte da equipe de saúde ou por conta do próprio enfermo.

Um paciente portador de tuberculose multirresistente pode transmitir o bacilo resistente aos seus contatos, sem que estes tenham utilizado os medicamentos específicos previamente. O contato que adoecer poderá ser portador de tuberculose multirresistente primária, ou seja, tuberculose multirresistente adquirida por contato com paciente portador de bacilos multirresistentes (ROCHA et al., 2008). Sendo assim, destaca-se como um das principais causas do surgimento de cepas resistentes a vários antibióticos, o uso incorreto dos medicamentos pelo enfermo.

Sem dúvida alguma, o ensino de temas relacionados na escola durante as aulas de ciências e biologia poderia ser eficaz na conscientização do uso correto destes fármacos, sendo feita uma espécie de prevenção contra tais fenômenos, assim como poderia ajudar a transparecer o quadro de desigualdades inerente a doenças negligenciadas, colaborando com a formação de cidadãos críticos e atuantes na sociedade.

A análise dos livros didáticos faz-se necessária pelo fato de que estes são o principal instrumento de trabalho do professor, sendo uma importante referência dos temas e da forma com que os conteúdos devem ser tratados. Contudo, têm-se observado deficiências diversas nos livros didáticos, que acabam tornando o trabalho docente menos eficaz. Além disso, segundo Freitas e Rodrigues (2007), o livro didático é fundamental para o processo de ensino-aprendizagem, pois é um instrumento pelo qual os alunos são introduzidos no contato de uma disciplina científica. Portanto este trabalho, que visa investigar a abordagem de um conteúdo científico específico, pode contribuir para o aprimoramento deste material.

É a valorização da responsabilidade em relação à saúde que é analisada neste estudo. A investigação deste tema é necessária e de grande importância, pois considera 
que os estudantes possam ser agentes transformadores da realidade em que vivem, na medida em que passam a conhecer os ciclos e a forma como essas doenças são transmitidas, contribuindo para benefícios em sua saúde e de sua família, e com exigências pela instauração de melhorias nas condições de vida da sociedade.

\section{METODOLOGIA}

Os oito livros didáticos aprovados pelo Programa Nacional do Livro Didático do Ensino Médio (PNLDEM) 2012 foram identificados como L1 a L8 (quadro 1), e analisados através de fichas de avaliação construídas por nós (quadros 2 e 3).

Quadro 1 - Livros didáticos avaliados neste estudo.

\begin{tabular}{|c|l|l|l|}
\hline Referência & \multicolumn{1}{|c|}{ Coleção } & \multicolumn{1}{|c|}{ Autor(es) } & \multicolumn{1}{|c|}{ Editora } \\
\hline L1 & Biologia & Gilberto R. Martho \& José Mariano Amabis & Moderna \\
\hline L2 & Biologia & César, Sezar \& Caldini & Saraiva \\
\hline L3 & Biologia Hoje & $\begin{array}{l}\text { Fernando Gewandsnajder \& Sérgio } \\
\text { Linhares }\end{array}$ & Ática \\
\hline L4 & Biologia & Pezzi, Gowdak \& Mattos & FTD \\
\hline L5 & Biologia para a Nova geração & V. Mendonça \& J. Laurence & $\begin{array}{l}\text { Nova } \\
\text { geração }\end{array}$ \\
\hline L6 & Novas Bases da Biologia & Nélio Bizzo & Ática \\
\hline L7 & Ser Protagonista Biologia & André Catani et al. & SM \\
\hline L8 & Bio & Sérgio Rosso \& Sônia Lopes & Saraiva \\
\hline
\end{tabular}

Para avaliar a relevância dada às doenças analisadas, de maneira preliminar analisamos se a obra trata, mesmo que superficialmente, da tuberculose e/ou hanseníase, e para analisar as informações que os autores julgam mais relevantes das patologias, cada livro foi submetido a diversas perguntas, ilustradas no quadro 2.

Quadro 2 - Aspectos avaliados nos livros didáticos

\begin{tabular}{|l|l|l|}
\hline Análise & Hanseníase & Tuberculose \\
\hline Aponta o agente etiológico? & ( ) Sim ( ) Não & ( ) Sim ( ) Não \\
\hline Aponta o modo de transmissão? & ( ) Sim ( ) Não & ( ) Sim ( ) Não \\
\hline $\begin{array}{l}\text { Descreve dados epidemiológicos que demonstram a alta } \\
\text { incidência das doenças no Brasil? }\end{array}$ & ( ) Sim ( ) Não & ( ) Sim ( ) Não \\
\hline Descreve os sintomas? & ( ) Sim ( ) Não & ( ) Sim ( ) Não \\
\hline Descreve o tratamento? & ( ) Sim ( ) Não & ( ) Sim ( ) Não \\
\hline $\begin{array}{l}\text { Traz alguma abordagem contextual (motivos socioeconômicos } \\
\text { do desenvolvimento da doença)? }\end{array}$ & ( ) Sim ( ) Não ( ) Sim ( ) Não \\
\hline
\end{tabular}

Por fìm, a questão da importância da utilização correta dos antibióticos foi avaliada, e a análise foi feita através das questões ilustradas no quadro 3: 
Quadro 3 - Questões analisadas a respeito do uso correto dos antibióticos

\begin{tabular}{|l|l|l|}
\hline Análise & Infecções em Geral & Tuberculose \\
\hline $\begin{array}{l}\text { Aponta a importância do uso adequado dos antibióticos para } \\
\text { a prevenção do surgimento de cepas resistentes? }\end{array}$ & $\begin{array}{l}\text { ( ) Sim } \\
\text { ( ) Parcialmente } \\
\text { ( ) Não }\end{array}$ & $\begin{array}{l}\text { ( ) Sim } \\
\text { ( ) } \\
\text { Parcialmente } \\
\text { ( ) Não }\end{array}$ \\
\hline $\begin{array}{l}\text { Se sim para a tuberculose, descreve o problema da } \\
\text { tuberculose multirresistente? }\end{array}$ & & $\begin{array}{l}\text { ( ) Sim } \\
\text { ( ) } \\
\text { Parcialmente } \\
\text { ( ) Não }\end{array}$ \\
\hline
\end{tabular}

\section{RESULTADOS E DISCUSSÃO}

A primeira pergunta a ser respondida nesta análise é se as doenças negligenciadas em questão foram ou não abordadas nos livros didáticos adotados pelas escolas públicas do Brasil. Afinal, como já abordado aqui, os livros didáticos são, muitas vezes, a única fonte de pesquisa dos alunos, e também podem funcionar como respaldo intelectual para o professor, de modo que dite o que deve ser ensinado ou não, numa determinada etapa do ensino. Ou seja, para muitos professores, se a informação existir no livro didático ela deve ser ensinada ao aluno, caso contrário seria uma informação desnecessária. Da mesma forma, se um determinado conteúdo estiver presente no livro didático deverá ser vista como importante pelo aluno.

Dos oito livros analisados, quatro abordam a hanseníase (L1, L3, L5 e L8) e cinco abordam a tuberculose (L1, L3, L5, L7 e L8), isto é, quatro dos oito livros analisados abordam as doenças hanseníase e tuberculose em seus textos, enquanto o L7 só aborda a tuberculose. Os livros L2, L4 e L6 não abordaram nenhuma das doenças na coleção; L2 e L4 trataram de outras doenças cujo agente etiológico também são bactérias, enquanto o L6 apenas cita as doenças, sem abordá-las.

E, ao se conhecer ou estudar uma doença infectocontagiosa, é esperado que seja informado qual é o agente causador da patologia, bactéria, vírus, protozoário, a qual espécie pertence, entre outras informações, por isso a questão: “aponta o agente etiológico?" Dos cinco livros que abordaram a tuberculose, todos (L1, L3, L5, L7 e L8) se preocuparam em informar o nome científico do agente etiológico, Mycobacterium tuberculosis, enquanto dos quatro livros que abordaram hanseníase, apenas três (L1, L3 e L8) informaram o agente etiológico da doença, Mycobacterium leprae. O L5, apesar de tratar de ambas as doenças em sua obra, preocupou-se em apontar o agente etiológico apenas da tuberculose.

Outra pergunta feita neste estudo diz respeito ao modo de transmissão destas doenças: “aponta o modo de transmissão?”. Ambas são transmitidas via contato direto com pacientes com índice baciloscópico positivo por meio da inalação de bacilos. Os 
livros que apontaram a transmissão da hanseníase foram L1, L5 e L8, e os que apontaram a da tuberculose, L1, L5, L7 e L8.

Neste quesito foi encontrado um erro conceitual no livro didático L1 (p.77) acerca da transmissão da hanseníase, o trecho a seguir foi retirado do livro em questão: “O contágio dá-se pelo contato com secreções contaminadas de pessoas doentes; as bactérias penetram no corpo através de pequenas lesões de pele e mucosas”. Entretanto, estudos atuais mostram que o modo de transmissão da hanseníase ainda é desconhecido, apesar de alguns autores acreditarem que ela seja transmitida por aerossóis no ar que são expelidos pelos doentes e posteriormente inalados pelas vias respiratórias (SCOLLARD et al., 2006), da mesma forma que ocorre com a tuberculose.

Depois, observamos se os livros forneciam dados epidemiológicos que chamassem a atenção dos alunos para tais doenças que apresentam alta incidência em nosso país, afinal o Brasil é o segundo país no ranking de novos casos de hanseníase, ficando atrás somente da Índia, além de fazer parte do grupo dos 20 países em atenção permanente da OMS no combate à tuberculose. Na pergunta "Descreve dados epidemiológicos que demonstram a alta incidência das doenças no Brasil?”, apenas o L7 contém dados epidemiológicos, e somente sobre a tuberculose. Estes dados escritos de forma adequada para os leitores - alunos do Ensino Médio - podem ser marcantes, fazendo com que o aluno tenha noção da situação emergencial destas doenças no país, tornando-os agentes transformadores na comunidade, pois se tornam capazes de difundir no núcleo familiar as informações apreendidas.

Para a pergunta "descreve os sintomas?", L1, L3, L5 e L8 descrevem os sintomas da hanseníase, enquanto L1, L3, L7 e L8 descrevem os da tuberculose. Estes dados demonstram uma maior preocupação dos autores em informar os sintomas característicos de cada doença. De fato, o conhecimento dos sintomas pelos alunos pode auxiliar num diagnóstico precoce, porém, a falta de uma política de saúde efetiva pode retardar o processo de diagnóstico confirmatório e início do tratamento, o que aumenta as chances do doente disseminar a doença na família.

“Descreve o tratamento?” Tuberculose e hanseníase são doenças conhecidas pela população há muitos anos. Os leprosos, como eram chamados aqueles que sofriam de hanseníase, sofriam muito preconceito e eram obrigados a se retirar da comunidade "pura" para locais distantes, da mesma forma os tuberculosos sofreram pela falta de um tratamento efetivo, e grande parte daqueles que contraíam a doença acabavam morrendo. 
Atualmente há antibióticos que conseguem eliminar a doença, pois são combinados com outros fármacos num sistema conhecido como poliquimioterapia, que é extremamente efetivo. Entretanto, há muitos que não sabem que estas têm cura, e acabam se afastando dos doentes, como se estes já estivessem destinados à morte. Assim, os livros didáticos poderiam contribuir mostrando o tratamento destas doenças, ressaltando que ambas têm cura, de modo a derrubar os mitos tratados anteriormente. Apesar disso, apenas o L1 apontou o tratamento da hanseníase, e os que apontaram o tratamento da tuberculose foram L1, L3, L7 e L8.

Por se tratar de doenças negligenciadas era esperado ao início da pesquisa que os livros abordassem motivos socioeconômicos que propiciassem o desenvolvimento das doenças, com a questão: “Traz alguma abordagem contextual (motivos socioeconômicos do desenvolvimento da doença)?" Porém, surpreendentemente, nenhum livro trouxe tal abordagem contextual. E aqui vemos as doenças sendo negligenciadas mais uma vez, reproduzindo-se o quadro de desatenção política. Exemplificando, o próprio Ministério da Saúde considera tais doenças um "forte entrave ao desenvolvimento dos países" (MINISTÉRIO DA SAÚDE, 2010), desconsiderando que o desenvolvimento dos países é que não leva em conta a situação de desigualdades.

Reverte-se aqui a responsabilização pela situação da negligência. Está claro que a pobreza aumenta a vulnerabilidade a estas doenças, sobretudo à tuberculose $\mathrm{e}$ hanseníase, nossos focos de análises. Analisando o modo de transmissão, o grande número de moradores por residência, a desnutrição, as casas precárias, a má circulação de ar e as instalações sanitárias pouco higiênicas, que normalmente caracterizam a condição de vida dos grupos carentes, aumentam a probabilidade de infecção por tais patologias. Em suma, o diagnóstico destas doenças é ainda tardio, o estado nutricional de populações carentes é precário, facilitando o desenvolvimento destas, observamos dificuldade de acesso aos serviços de saúde, que são por sua vez precários, e nada disso foi apontado por nenhum livro didático analisado.

Também já é sabido que o uso incorreto dos antibióticos contribui para o surgimento de cepas bacterianas resistentes aos antibióticos usuais. Este uso incorreto está, na maioria das vezes, ligado à interrupção do tratamento antes do tempo sugerido pelo profissional de saúde. Somada à dificuldade dos pacientes em sua qualidade de vida e em obterem um serviço de saúde de qualidade, estes costumam interromper o uso logo após o desaparecimento dos sintomas, desta forma ocorre uma seleção artificial das bactérias mais resistentes. E esta cultura de desinformação se propaga à medida que o 
tratamento é negligenciado nos materiais didáticos, já que apenas dois dos livros analisados (L4 e L7), abordaram a questão do uso incorreto dos antibióticos e o surgimento das cepas de bactérias resistentes. O impacto da conscientização sobre o uso correto dos antibióticos nas aulas de ciências e biologia é de extrema importância, não só para o próprio aluno e sua família, mas também para a comunidade, afinal as pessoas que inconscientemente fazem o uso incorreto de antibióticos podem transmitir a outras pessoas tais cepas resistentes, aumentando as chances de um problema generalizado. $\mathrm{O}$ agravo é ainda maior quando se trata da tuberculose, já que desenvolve a cepa multirresistente.

A tuberculose multirresistente é uma das principais causas de mortalidade dentro da doença, e tem chamado muito a atenção das autoridades de saúde devido ao tempo, custo e complexidade do seu tratamento em relação à tuberculose usual. Em 2008 havia uma estimativa de 440000 pessoas com tuberculose multirresistente no mundo, com 150000 mortes pela doença na forma multirresistente no mesmo ano. Atualmente acredita-se que 3,6\% dos novos casos de tuberculose sejam da forma multirresistente (WHO, 2010). E como observado nas nossas análises, nenhum livro se preocupou em discutir a problemática atual da tuberculose multirresistente. Os dados sobre esta forma da doença são alarmantes e parece um retrocesso no tratamento da tuberculose, afinal há poucos anos a doença parecia ter tido um desfecho, em última análise, feliz, porém com a forma multirresistente da doença, a luta pela erradicação parece ter apenas começado. A discussão da tuberculose multirresistente nas salas de aula pode contribuir para a formação do aluno enquanto cidadão tanto para fundamentar discussões sobre doenças e políticas de saúde, bem como para formação do aluno como agente transformador do ambiente e multiplicador do conhecimento biológico.

As doenças trabalhadas aqui requerem uma retomada histórica, afinal são doenças conhecidas há muitos anos, que marcaram vários períodos da história do Homem na Terra. A hanseníase, por exemplo, foi a primeira doença humana transmitida por bactérias, identificada, em 1874 por Hansen, e este fato não foi abordado em nenhum livro didático. Além disso, há evidências históricas de tuberculose em ossos humanos pré-históricos encontrados na Alemanha, 8000 A.C. (CONDE, SOUZA e KRITSKI, 2002). Deste modo, a abordagem histórica, bem como a social, contribuem para tornar esta série de conhecimentos contextualizada, fazendo com que a assimilação destes conhecimentos seja facilitada e que o conteúdo seja realmente apreendido. 
A falta de contextualização histórico-filosófica e social na abordagem destes conteúdos nos livros didáticos, aliada a outros mecanismos textuais, acabam valorizando a memorização das informações contidas no texto pelos alunos. Sequências de informações tratadas de forma inadequada nos livros didáticos foram vistas, como por exemplo: "a doença é transmitida pela bactéria $X$, que é passada de pessoa a pessoa quando inalada, o tratamento é feito com antibióticos e hoje poucas pessoas que têm acesso ao tratamento correto, morrem". Este mesmo tema tratado de uma forma significativa pode levar a uma atividade reflexiva dos alunos, e por consequência estes podem modificar seus hábitos e desenvolver atitudes esperadas pelo processo educativo.

Além dos problemas tratados até aqui, somamos o fato de que alguns professores se utilizam do próprio livro didático como fonte de estudos sobre a referida temática, ou seja, dos conteúdos a serem tratados em cada etapa do período escolar, o que os leva a uma incapacidade na detecção dos erros e desatualizações evidenciados no estudo (CANALLE, TREVISAN e LATTARI, 1997), maximizando a problemática do seu uso incorreto. Neste sentido, o surgimento em 1994, do Programa Nacional do Livro Didático, onde os livros passam a ser avaliados representando menos equívocos e maior clareza com os conteúdos, não deve ser um incentivo para os professores os utilizarem como fonte única de pesquisa e prática pedagógica.

De forma alguma os livros didáticos podem substituir a atividade construtiva do professor, nem a dos alunos na aquisição das aprendizagens, mas representa um recurso de extrema importância que, se bem utilizado, não só potencializa o processo de aprendizagem como oferece ideias, propostas e sugestões que enriquecem o trabalho docente. Na verdade, cada vez mais devem ser utilizados recursos audiovisuais disponíveis na web e em coletâneas didáticas, além do uso de livros paradidáticos e reportagens de revistas de divulgação científica no cotidiano escolar, sem contar com as possíveis saídas de campo e visitas a museus, planetários, laboratórios, feiras e exposições. A interação destes recursos com a sala de aula auxilia claramente na aprendizagem significativa dos alunos (AUSUBEL, 1976 apud SCHNETZLER, 1992).

Para Santos (s.d.), é necessário “desequilibrar” as redes neurais dos alunos, ou seja, propor atividades que os tragam para o centro da sala de aula, afinal eles são os agentes principais do processo de aprendizagem. Os docentes em seus planejamentos devem buscar formas criativas e estimuladoras de desafiar as pré-concepções dos alunos. $\mathrm{O}$ autor ainda ressalta em seu ensaio que esta atitude torna a aula mais prazerosa para os alunos e mais gratificante para os educadores. 
Entretanto, situações de aprendizagem não são oferecidas nos livros didáticos de forma geral, como foi observado nos achados desta pesquisa, e a reprodução das desigualdades sociais é perpetuada pela omissão, representativa da negligência. Esta constatação traz à tona nossa grande preocupação: os professores que usam o livro didático como ditador da sequência de conteúdos a ser ensinada promoverão alguma situação de aprendizagem? Promoverão algum debate sociopolítico acerca da situação de saúde e de vida da população? Tendo um olhar mais descentralizado, são inúmeras as competências que deixam de ser adquiridas pelos alunos em salas em que os professores não traçam estratégias de ação de maneira mais contextualizada, que não utilize exclusivamente o livro como respaldo intelectual.

\section{CONSIDERAÇÕES FINAIS}

A análise dos referidos livros nos forneceu um panorama de como as doenças negligenciadas: tuberculose e hanseníase estão sendo abordadas nos livros didáticos e, por consequência, supomos que nas salas de aula. E este panorama não nos leva a ter boas perspectivas, afinal $62,5 \%$ dos livros trataram de alguma forma a tuberculose e $50 \%$ a hanseníase, um índice insatisfatório, já que o desejável seria que o assunto fosse adequadamente contemplado em todos.

$\mathrm{Na}$ atualidade os livros didáticos vêm sendo usados como a principal ferramenta pedagógica e de pesquisa (FREITAS e RODRIGUES, 2007) para acolher a demanda das políticas curriculares, que muitas vezes nem atendem às necessidades da comunidade em que o aluno está inserido. Entretanto, sem esquecer sua importância no cotidiano escolar, os livros didáticos apresentam lacunas de conhecimentos, além de erros conceituais, que precisam ser preenchidos e corrigidos pelo professor durante as abordagens em sala de aula, visando atender de forma mais adequada às necessidades discentes, com o intuito de tornar significativo o conhecimento a estes.

Competências indicadas nas Orientações Educacionais Complementares (BRASIL, 2002) aos Parâmetros Curriculares Nacionais são encaradas como um desafio ao professor, pois ultrapassam a lógica que estrutura a ciência, ao passo que se baseiam em situações de aprendizagem que tenham sentido para o aluno, que os instrumentalize em sua ação e participação em contextos relevantes em suas vidas.

Esta inversão na tradição do ensinar tem chance de proporcionar uma assimilação de conhecimentos realmente significativa para o aluno. No contexto deste trabalho destaca-se a competência a seguir: 
Perceber os efeitos positivos, mas também perturbadores, da ciência e da tecnologia na vida moderna como, por exemplo, reconhecer o papel dos antibióticos na preservação da vida e, ao mesmo tempo, as alterações que esses medicamentos vêm introduzindo nas populações microbianas e as consequências dessas modificações para a manutenção da saúde dos indivíduos ou, ainda, compreender a importância do uso de defensivos agrícolas para a produção de alimentos e os efeitos danosos dessas substâncias nos ecossistemas. (BRASIL, 2002, p. 40).

Como visto acima, esta situação de aprendizagem aplica-se a um dos parâmetros avaliados neste estudo, que visa à orientação para o uso correto dos antibióticos, como forma de prevenção ao surgimento de cepas de bactérias resistentes, como é caso da tuberculose multirresistente. Esta situação de aprendizagem deve ocorrer nas salas de aula, com o objetivo de instrumentar o discente na avaliação do desenvolvimento tecnológico contemporâneo, juntamente com a análise dos impactos ao ambiente e ao homem dos avanços nesta área.

E por fim, é preciso além de tudo, destacar o viés que transpassa toda esta discussão a respeito do tema: o fato de que estas doenças têm sido politicamente negligenciadas. Por mais que exista preocupação com elas, fato observado em congressos internacionais em saúde pública, estas ainda ocupam uma posição secundária nas agendas nacionais e internacionais de saúde, não sendo alvos de interesse da indústria farmacêutica, nem sequer da Política Nacional de Medicamentos, já que contam com baixo investimento em capacitação tecnológica, e em recursos humanos de forma geral (OLIVEIRA, LABRA e BERMUDEZ, 2006). Assim, o preparo do aluno com estes conhecimentos contribuiria para a inversão dos parâmetros atuais de desigualdades no setor da saúde, norteados pela questão que não se cala nesta situação: negligenciadas por quê? (MOREL, 2006).

\section{REFERÊNCIAS}

BRASIL. Ministério da Educação. Parâmetros curriculares nacionais - Ciências Naturais : Ensino de quinta a oitava séries, 1998.

BRASIL. Ministério da Educação. PCN+ Ensino Médio - Orientações Educacionais Complementares aos Parâmetros Curriculares Nacionais - Ciências da Natureza, Matemática e suas Tecnologias, 2002.

CANALLE, J. B. G.; TREVISAN, R. H. e LATTARI, C. J. B. Análise do conteúdo de astronomia de livros de geografia de primeiro grau. Caderno Catarinense de Ensino de Física. v 14, n 3, pp. 254-263, 1997. 
COELHO, A.G.V., ZAMARIOLI, L.A., TELLES,M.A., FERRAZOLI, L. e WALDMAN, E.A. A study of multidrug-resistant tuberculosis in risk groups in the city of Santos. Mem. Inst. Oswaldo Cruz. v. 107, n. 6, pp.760-766, 2012.

CONDE, M. B., SOUZA, G. M. e KRITSKI, A. L. Tuberculose sem medo. $1^{\text {a }}$ ed. São Paulo: Editora Atheneu, 2002.

FREITAS, N.K.; RODRIGUES, M.H.; O livro didático ao longo do tempo: a forma do conteúdo. Projeto de Mestrado (Mestrado em Artes Visuais) Universidade do Estado de Santa Catarina-UDESC, 2007. Disponível em:

http://www.ceart.udesc.br/revista_dapesquisa/volume3/numero1/plasticas/melissaneli.pdf Acesso em 20 mar 2014.

MINISTÉRIO DA SAÚDE. Doenças negligenciadas: estratégias do Ministério da Saúde. Rev Saúde Pública. v.44, n.1. pp.200-202, 2010.

MOREL, C.M. Inovação em saúde e doenças negligenciadas. Cad. Saúde Pública. v.22, n.8, pp.1522-1523, 2006.

OLIVEIRA, E.A., LABRA, M.E. e BERMUDEZ, J. A produção pública de medicamentos no Brasil: uma visão geral. Cad. Saúde Pública v.22 n.11, pp. 23792389, 2006.

ROCHA, J.L., DALCOLMO, M.P., BORGA, L. FEDELE, A. e MARQUES, M.G. Tuberculose multirresistente. Pulmão. v. 17, n.1, pp. 27-32, 2008.

SANTOS, J.C.F. O papel do professor na promoção da aprendizagem significativa. s.d. Disponível em http://www.famema.br/ensino/capacdoc/docs/papelprofessorpromocaoaprendizagemsig nificativa.pdf Acesso em 20 mar 2014.

SANTOS, E.T. e GOMES, Z.M.S. Política de Tuberculose no Brasil - Uma perspectiva da sociedade civil. Rev. Saúde Pública. v.41, supl.1, pp.111-116, 2007.

SCOLLARD, D.M., ADAMS, L.B., GILLIS, T.P, KRAHENBUHL, J.L. e WILLIAMS, D.L. The continuing challenges of leprosy. Clin Microbiol Rev. v. 19, n. 2, pp. 338-381, 2006.

SCHNETZLER, R. P. Construção do conhecimento e ensino de Ciências. Em Aberto, ano 11, n. 55, 1992 Disponível em:

http://emaberto.inep.gov.br/index.php/emaberto/article/viewFile/813/731 Acesso em 20 mar 2014.

WHO. Multidrug and extensively drug-resistant TB (M/XDR-TB): 2010 global report on surveillance and response. World Health Organization (WHO), 2010. Disponível em: http://whqlibdoc.who.int/publications/2010/9789241599191_eng.pdf Acesso em 20 mar 2014. 